Article

\title{
Air Gasification of Agricultural Waste in a Fluidized Bed Gasifier: Hydrogen Production Performance
}

\author{
W. A. Wan Ab Karim Ghani ${ }^{1, *}$, Reza Alipour Moghadam ${ }^{1}$, M. A. Mohd Salleh ${ }^{1}$ and \\ A. B. Alias ${ }^{2}$ \\ 1 Universiti Putra Malaysia, 43400 Serdang, Selangor, Malaysia; E-Mails: \\ moghadam.reza@yahoo.com; asalleh@eng.upm.edu.my \\ 2 Chemical Engineering, Universiti Teknologi MARA Malaysia, 54500 Shah Alam, Selangor, \\ Malaysia
}

* Author to whom correspondence should be addressed; E-Mail: wanaz@eng.upm.edu.my; Tel.: +60389466287; Fax: +603-86567120

Received: 17 April 2009; in revised form: 11 May 2009 / Accepted: 12 May 2009 /

Published: 19 May 2009

\begin{abstract}
Recently, hydrogen production from biomass has become an attractive technology for power generation. The main objective pursued in this work is to investigate the hydrogen production potential from agricultural wastes (coconut coir and palm kernel shell) by applying the air gasification technique. An experimental study was conducted using a bench-scale fluidized bed gasifier with $60 \mathrm{~mm}$ diameter and $425 \mathrm{~mm}$ height. During the experiments, the fuel properties and the effects of operating parameters such as gasification temperatures $\left(700\right.$ to $\left.900^{\circ} \mathrm{C}\right)$, fluidization ratio $(2$ to $3.33 \mathrm{~m} / \mathrm{s})$, static bed height (10 to $30 \mathrm{~mm}$ ) and equivalence ratio (0.16 to 0.46$)$ were studied. It was concluded that substantial amounts of hydrogen gas (up to $67 \mathrm{~mol} \%$ ) could be produced utilizing agricultural residues such as coconut and palm kernel shell by applying this fluidization technique. For both samples, the rise of temperature till $900^{\circ} \mathrm{C}$ favored further hydrocarbon reactions and allowed an increase of almost $67 \mathrm{~mol} \%$ in the release of hydrogen. However, other parameters such as fluidizing velocity and feed load showed only minor effects on hydrogen yield. In conclusion, agricultural waste can be assumed as an alternative renewable energy source to the fossil fuels, and the environmental pollution originating from the disposal of agricultural residues can be partially reduced.
\end{abstract}


Keyword: hydrogen; agricultural waste; fluidized bed

\section{Introduction}

Agricultural residues are potentially an attractive feedstock for producing energy as their use contributes little or no net carbon dioxide to the atmosphere. Agricultural production in Malaysia continued to record positive growth from 2000 to 2005 and is expected to expand more in 2010 consistent with the government policies [1]. In Malaysia, the major agricultural products are palm oil, sawlogs, paddy and tropical fruits of which more than 70 million tones are collected annually. Significant amount of wastes and residues also called agricultural wastes are produced from the postprocessing of these products. The processing of this waste has become a technological issue that has attracted the attention of numerous researchers. Presently, the most conventional way of handling these waste streams is to burn them with energy recovery or for landfilling. However, both combustion and landfill use cause secondary pollution problems. Novel disposal technologies are in high demand to provide for more energy efficient and environmentally and economically sound solutions. An alternative to these combustion and landfill uses is gasification. Thermochemical gasification of biomass is a well-known technology that seems to be a feasible application and has been developed for industrial applications [2-5]. This technology has been identified as a possible system for producing renewable hydrogen. The transformation of biomass into hydrogen-rich gas is a suitable source for energy production due to the advantages typical biomass (renewable character, net below zero $\mathrm{CO}_{2}$ emissions, possibility of using residues generated from agriculture activities). Most of the research spurred by this interest has been techno-economic in nature, based on gasifier performance data acquired during system proof of concept testing. However, less emphasis has been given to experimental investigation of hydrogen production via biomass gasification, the focus of this paper.

Most of the researchers have employed oxygen and steam as a gasifying agent and operated under a high temperature slagging mode. This was due to the fact that high carbon conversion can be achieved in a short residence time, and tar production should be low. However, the slag may be corrosive to the gasifier and can cause smelt-water explosions if improperly handled [4]. A fluidized bed reactor operating under medium temperature (around $900-1,000^{\circ} \mathrm{C}$ ), is an alternative to agricultural waste gasification with air as gasifying agent. The air gasification process can convert these solid agricultural residues into a synthesis gas that is suitable for use in electricity production or for the manufacture of chemicals, hydrogen or transportation fuels. The gas produced from biomass gasification can be directly used as fuel in internal combustion engines or gas turbines [3]. An advantage of air gasification over other gasifying agents is to simplify the gasification process and reduce operating and maintenance cost because air separation to obtain oxygen is a more complex and expensive process. On the other hand, in the case of air gasification, its nitrogen content remains as an inert component in the produced gas that dilutes the fuel gas and leads to a lower calorific value fuel [4]. Although the feasibility of the air gasification process has been demonstrated with different feedstocks, less emphasis has been given to experimental investigation of hydrogen production via agricultural wastes (biomass) gasification, the focus of this paper [3-10].The transformation of biomass into hydrogen-rich 
gas is a suitable source for energy production due to the typical advantages of biomass (renewable character, net below zero $\mathrm{CO}_{2}$ emissions, etc). The production of hydrogen from biomass was described as listed reactions below [8]:

$\begin{array}{ll}\text { Oxidation reaction: } & \mathrm{C}+\mathrm{O} 2 \rightarrow \mathrm{CO}_{2} \\ & \mathrm{C}+1 / 2 \mathrm{O} 2 \rightarrow \mathrm{CO} \\ \text { Boudouard: } & \mathrm{C}+\mathrm{CO} 2 \rightarrow 2 \mathrm{CO} \\ \text { Water gas: } & \mathrm{C}+\mathrm{H}_{2} \mathrm{O} \rightarrow \mathrm{CO}+\mathrm{H}_{2} \\ \text { Methanation: } & \mathrm{C}+2 \mathrm{H}_{2} \rightarrow \mathrm{CH}_{4} \\ \text { Water gas shift: } & \mathrm{CO}+2 \mathrm{H}_{2} \mathrm{O} \rightarrow \mathrm{CO}_{2}+\mathrm{H}_{2}\end{array}$

The quality of the gas produced (composition, production of $\mathrm{CO}, \mathrm{H}_{2}, \mathrm{CO}_{2}$ and $\mathrm{CH}_{4}$ and energy content) and the gasification performance (gas yield) depend upon feedstock origin, gasifier design and operating parameters such as temperature, static bed height, fluidizing velocity, equivalence ratio, gasifying agent, catalyst and others, which are explain elsewhere [5, 7, 9-16]. Warnacke demonstrated that the gas composition was a function of gasifier design whereby the same fuel may give different calorific values with different gasifiers [11]. Among all designs, the fluidized bed gasifier has been shown to be a versatile technology capable of burning practically any waste combination with high efficiency. The significant advantages of fluidized bed combustors over conventional combustors include their compact furnaces, simple design, effective burning of a wide variety of fuels, relatively uniform temperature, and the ability to reduce emissions such as nitrogen oxide and sulphur dioxide gas [17].

In this work, a laboratory scale fluidized bed was used to investigate the characteristics of gasification of agricultural wastes. The effect of gasification temperatures, fluidization ratio, static bed height and equivalence ratio (ER) on gas composition, gas yield and gas heating value were studied.

\section{Experimental Section}

\subsection{Experimental Set Up}

Agricultural wastes (palm kernel and coconut shell) from a local palm mill and coconut processing site were selected for this study. The samples were air dried for 2 to 3 days to remove moisture and to facilitate crushing. The proximate and ultimate analyses of the feed stock as reported in Table 1.

The schematic diagram of the experimental facility used in this study is shown in Figure 1. The gasifier was specially designed for operation under atmospheric or pressurized conditions. The test facility consists of three main parts: the gasifier, the liquid trap and the gas sampling section. The fluidized bed gasifier, having an internal diameter of $60 \mathrm{~mm}$ and height of $425 \mathrm{~mm}$, was made of heat resistant stainless steel and surrounded by two individually controlled electric heaters (located at the dense bed and freeboard zone, respectively) were used to supply heat for startup and for countering the heat loss during operation. The spaces between the reactor and the outside pressure vessel were filled with fiber insulation to counter the heat loss from the reactor. Two K-type thermocouples (T1 and T2) were installed across the reactor: the probe $\mathrm{T} 1$ in the bed zone, defined as the gasification reaction 
zone (at the height of $100 \mathrm{~mm}$ above the distributor) and one probe in the freeboard (at the height of $300 \mathrm{~mm}$ above the distributor). The samples were delivered into the dense bed zone of the gasifier using a calibrated feeder. Prior to gasification tests, all the fuel samples were ground to less than $300 \mu \mathrm{m}$ in order to ensure the homogeneity on the biomass composition. Air was supplied by a compressor and heated to $400^{\circ} \mathrm{C}$ by an air-electric pre-heater, and then the hot air entered the gasifier via a multi-orifice plate distributor. The clean gas was then sent to a water cooler to separate the condensed and un-condensed tars and steam. Sampling gas bags were employed to collect the product gas just leaving the cooler for off line gas analysis.

Table 1. Fuel properties.

\begin{tabular}{lcc}
\hline & Palm kernel shell & Coconut shell \\
\hline Moisture content (\% wet basis) & 7.96 & 4.89 \\
Proximate analysis (wt \% dry basis) & & \\
Volatile matter & 72.47 & 30.62 \\
Fixed carbon & 18.56 & 26.41 \\
Ash & 8.97 & 42.98 \\
Ultimate analysis (wt\% dry basis) & & \\
Carbon & 51.63 & 45.24 \\
Hydrogen & 5.52 & 5.04 \\
Nitrogen & 1.89 & 1.46 \\
Sulfur & 0.05 & 0.06 \\
Oxygen (by different) & 40.91 & 48.2 \\
\hline Higher Heating Values (HHV) (MJ/kg) & 22.97 & 16.07 \\
\hline
\end{tabular}

Figure 1. Schematic diagram of the experimental apparatus.

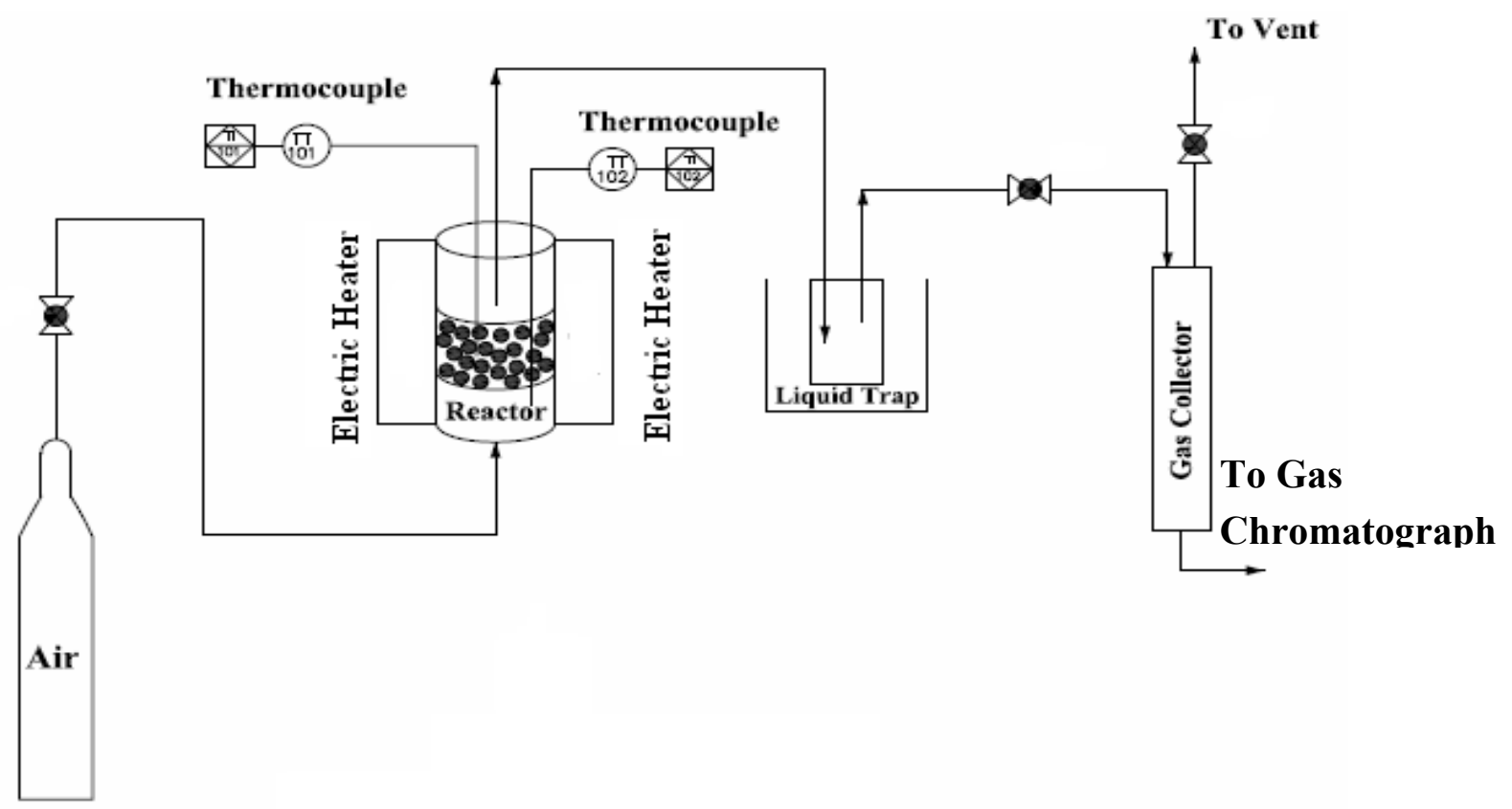




\subsection{Experimental Procedures}

The experimental schedule has been designed in order to analyze the individual effects of the main parameters governing the produced gas quality (composition, production) and the gasification performance (gas yield, energy content), such as: a) varying the temperature (700 to $900^{\circ} \mathrm{C}$ ); b) varying the fluidizing ratio $\left(2.0\right.$ to $\left.3.3 \mathrm{~ms}^{-1}\right)$; c) varying the average static bed height (10 to $30 \mathrm{~mm}$ ) and d) varying the air to fuel ratio or equivalence ratio (ER) (0.15 to 0.45). At the start-up of each experimental run, the agricultural waste (coconut and palm kernel shell) was added to the hopper; the gasifier and furnace heaters for air gasification and the controllers were set at the selected operating temperatures. At the beginning of the experiment, the reactor was charged with $24 \mathrm{~g}$ silica sand as bed material, which helped in stable fluidization and better heat transfer. After the bed temperature reached the desired level and remained steady, the air compressor was turned on to force the air through the pre-heater and air distributor into the reactor. When the bed temperature became steady, the samples were fed and the test began. Three samples were taken at an interval of $3 \mathrm{~min}$ after the test ran in a stable state. Normally each experiment was repeated two times and the results were in good agreement. A sample stream for permanent gas analysis was extracted from the process directly after the main filter housing. The gas stream was passes through a water cooled heat exchanger followed by a condenser trap and a coalescing filter. Grab samples of cool, clean and dry gas were collected and analyzed off-line for the permanent gases $\mathrm{H}_{2}, \mathrm{CO}, \mathrm{CH}_{4}$ and $\mathrm{CO}_{2}$ using a gas chromatography (GC)(Autosystem, Perkin Elmer,) equipped with a thermal conductivity detector (TCD). A GC calibration was performed using a certified standard gas prior each test.

\section{Results and Discussion}

Average properties of the fuel used for the tests are shown in Table 1. The composition of the fuel is quite similar to the typical fuel used in the theoretical biomass types. Fuel moisture contents for palm kernel shell and coconut shell are $5 \%$ and $8 \%$, respectively. Fuel higher heating value was determined to be 22 and $16 \mathrm{MJ} \mathrm{kg}^{-1}$, respectively.

\subsection{The Effect of Temperature}

Figure 2 shows the gas composition obtained at five different temperatures $\left(700\right.$ to $\left.900^{\circ} \mathrm{C}\right)$ and at constant static bed height and fluidization velocities, expressed as the ratio of superficial fluidizing velocity to minimum fluidizing velocity $\left(\mu / \mu_{\mathrm{mf}}\right)$ calculated from the air $800^{\circ} \mathrm{C}, 0.1 \mathrm{Mpa}$ condition were $200 \mathrm{~mm}$ and 2.7, respectively. The gas composition obtained showed that the Hydrogen $\left(\mathrm{H}_{2}\right)$ concentration increased significantly from $43-67 \%$ for coconut shell and $56-66 \%$ for palm kernel shell, based on dry inert-gas with temperature and the content of $\mathrm{CH}_{4}$ showed an opposite trend. This is in accordance with Le Chatelier's principle; higher temperatures favor the reactants in exothermic reactions and favor the products in endothermic reactions. Therefore, the endothermic reactions of methane reforming reaction (Eqn. 5) were verified this theory. The content of $\mathrm{CO}$ was mainly determined by the Bourdard reaction (Eqn. 3) and it is an exothermic reaction. Higher temperature was not favorable for $\mathrm{CO}$ production, thus the content of $\mathrm{CO}$ decreased with temperature. However, in the 
present work an obvious increase was found in $\mathrm{CO}$ concentration at higher temperature in the case of coconut shell. This may due on the one hand, to a higher partial gasification of carbon and on the other hand, to the endothermic character of Bourdouard equilibrium (Eq. 3) which does also justify the decrease in $\mathrm{CO}_{2}$. At a given pressure the equilibrium gas composition for this reaction is only a function of the temperature employed [8]. This also caused by the higher bed temperature condition as the temperature increases. The higher bed temperature resulted in a higher rate of exothermic reactions. This is in line with the observation of Mansary et al. [18] who studied the air gasification of rice in a fluidized bed.

Figure 2. Effect of temperature on gas composition for palm kernel shell (PKS) and coconut shell (CS).

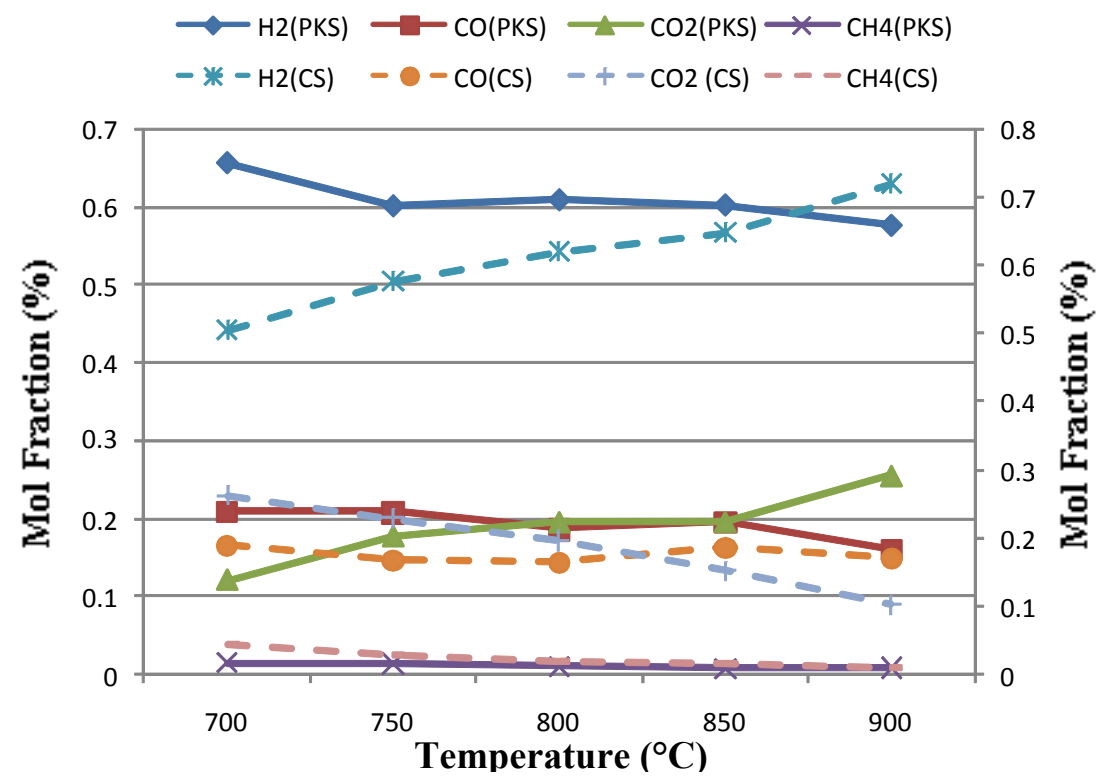

The information on gas yield and gas quality per unit mass of agricultural wastes is important as it reflects the capability of the agricultural wastes being converted to different products. Table 2 presents the gas yield and gas heating values obtained in the tests, referred to the agricultural wastes fed, and achieved by variation of the reactor temperatures while keeping the static bed height and fluidization velocities constant. A strong influence of temperature on the gas yield and quality was observed. Gas yield increases with increasing temperature as shown in Table 2 gas yield increased ranging from 0.91 to $2.95 \mathrm{~kg} / \mathrm{kg}$ biomass and $2.36-5.90 \mathrm{~kg} / \mathrm{kg}$ biomass for coconut shell and palm kernel shell, respectively. Similarly, to the gas heating value, where the product gas Lower heating value (LHV) showed a maximum values at $1174 \mathrm{KJ} / \mathrm{NM}^{3}$ and $3711 \mathrm{KJ} / \mathrm{NM}^{3}$ for both coconut shell and palm kernel shell, respectively, at the temperature $850^{\circ} \mathrm{C}$. 
Table 2. Gas yield and LHV at different temperature.

\begin{tabular}{|c|c|c|c|c|c|}
\hline Reactor temperature $\left({ }^{\circ} \mathrm{C}\right)$ & 700 & 750 & 800 & 850 & 900 \\
\hline \multicolumn{6}{|l|}{ Gas yield (mol/kg biomass) } \\
\hline coconut shell & 0.91 & 1.81 & 1.42 & 2.12 & 2.95 \\
\hline palm kernel shell & 2.36 & 3.46 & 4.37 & 5.25 & 5.90 \\
\hline \multicolumn{6}{|l|}{ Gas LHV $\left(\mathrm{kJ} / \mathrm{NM}^{3}\right)$} \\
\hline coconut shell & 930 & 1033 & 1174 & 1874 & 2384 \\
\hline palm kernel shell & 2783 & 3276 & 3711 & 4451 & 3720 \\
\hline
\end{tabular}

\subsection{Effect of Fluidization Ratio}

Figure 3 presents the gas produced composition as a function of the fluidization ratio with constant static bed height, temperature and equivalence ratio (ER). Increasing the fluidization ratio from 2.20 to $3.30 \mathrm{~m} / \mathrm{s}$ decreased the combustible gas components $\mathrm{CO}$ from 0.17 to $0.15 \mathrm{~mol} \%$ and 0.32 to $0.13 \mathrm{~mol} \%$ for coconut shell and palm kernel shell, respectively. However, a different trend was observed for $\mathrm{H}_{2}$, where the fraction decreased about $17 \%$ for coconut shell but increased up to $26 \%$ for palm kernel shell with increased fluidization ratio. The fluidization velocities not only provide good mixing between gas and solid in the fluidized bed but also reduce the bed temperatures, which resulted in an increase of heat losses. As the bed temperatures decreases, this condition will not favored the conversion of carbon into combustible gases. On the contrary, and increases of $\mathrm{CH}_{4}$ content were observed as higher fluidization ratio which verified the above statement. While, the content of $\mathrm{CO}_{2}$ increased about $43 \%$ and $62 \%$ for coconut shell and palm kernel shell, respectively with the increase in fluidization velocity which is again reflects the less efficient conversion process as fluidization ratio increase. The variations in the gas composition with fluidization velocity caused a decrease of the gas yield and LHV (see Table 3). Xiao et al. [4] found the same trend, which can be attributed to rapid exothermic reactions and hence a higher $\mathrm{CO}_{2}$ content at the expense of most combustible fractions. As fluidizing velocity increased, more carbon can be converted through reaction 1 and 6.

Figure 3. Effect of fluidization ratio on gas composition for palm kernel shell (PKS) and coconut shell (CS).

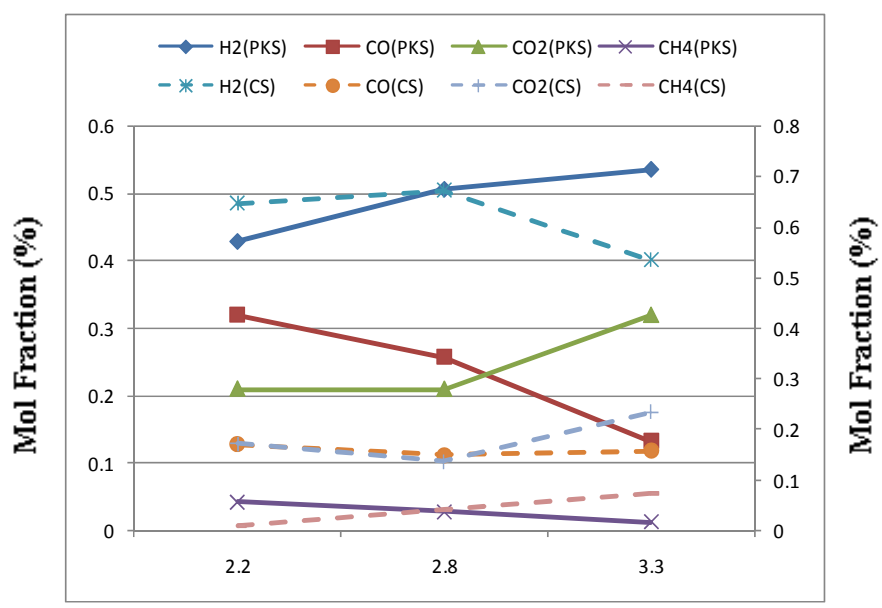

Fluidization ratio 
Table 3. Gas yield and LHV at different fluidization ratio.

\begin{tabular}{llll}
\hline Fluidization ratio $\left(\boldsymbol{\mu} / \boldsymbol{\mu}_{\mathbf{m f}}\right)$ & $\mathbf{2 . 2 0}$ & $\mathbf{2 . 8 0}$ & $\mathbf{3 . 3 3}$ \\
\hline Gas yield (mol/kg biomass) & & & \\
a) coconut shell & 0.60 & 0.32 & 0.26 \\
b) palm kernel shell & 3.15 & 3.57 & 4.42 \\
Gas LHV (kJ/NM $\left.{ }^{3}\right)$ & & & \\
a) coconut shell & 484 & 292 & 279 \\
b) palm kernel shell & 4607 & 1756 & 1961 \\
\hline
\end{tabular}

\subsection{Effect of Static Bed Height}

Figure 4 and Table 4 shows the influence of static bed height on the gas composition, gas yield and gas quality. For a fixed fluidizing velocity, increasing the bed height would prolong the product's residence time in the high temperature dense bed. This will favor secondary cracking reactions of tars and heavy hydrocarbons, and char gasification reactions, which will caused an increase in the gas yield [5]. As shown in Figure 4, the $\mathrm{H}_{2}$ and $\mathrm{CO}$ content increased from 0.68 to $0.70 \mathrm{~mol}$ gas $/ \mathrm{mol}$ biomass and 0.06 to $0.17 \mathrm{~mol}$ gas $/ \mathrm{mol}$ biomass for coconut shell but for palm kernel shell $\mathrm{H}_{2}$ decrease from 0.70 to $0.47 \mathrm{~mol}$ gas $/ \mathrm{mol}$ biomass and $\mathrm{CO}$ increase from 0.19 to $0.25 \mathrm{~mol}$ gas $/ \mathrm{mol}$ biomass. Meanwhile, the $\mathrm{CH}_{4}$ content decreased slightly from 0.04 to $0.011 \mathrm{~mol}$ gas $/ \mathrm{mol}$ biomass for coconut shell but an increase in $\mathrm{CH}_{4}$ from 0.023 to $0.042 \mathrm{~mol}$ gas $/ \mathrm{mol}$ biomass for palm kernel shell was observed. However, $\mathrm{CO}_{2}$ content significantly increased in both cases, with averages of $11 \%$ and $38 \%$ for coconut shell and palm kernel shell, respectively. The gas yield was decreased when the static bed height was increased to $30 \mathrm{~mm}$. This indicated that there might an optimum bed height for a particular ER, at which the gas yield reached a maximum. This can be explained by the fact that a significant change of the hydrodynamic conditions due to the formation of larger bubbles in the bed height.

Figure 4. Effect of static bed height on gas composition for palm kernel shell (PKS) and coconut shell (CS).

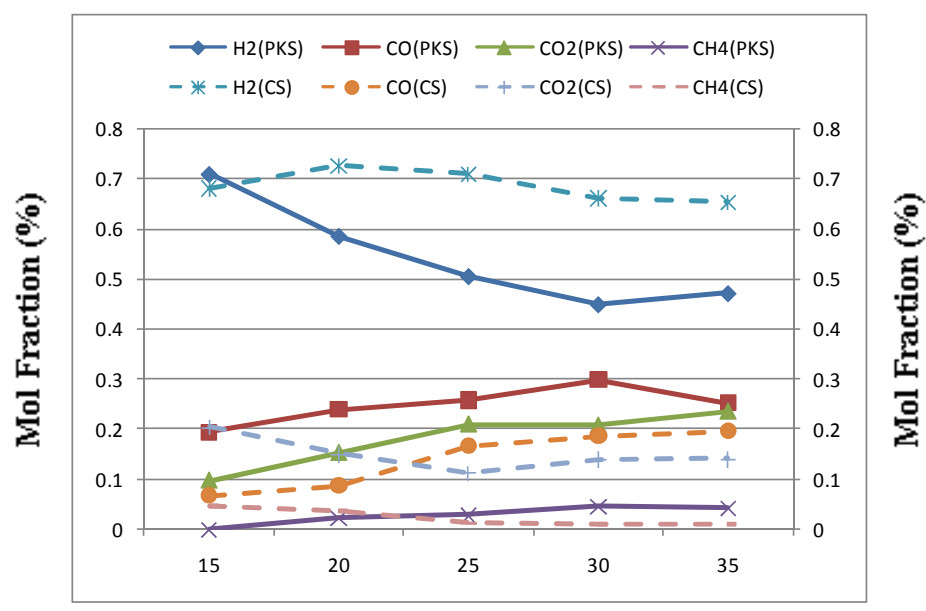

Static Bed Height (cm) 
Table 4. Gas yield and LHV at different static bed height.

\begin{tabular}{|c|c|c|c|c|c|}
\hline Bed Height (mm) & 15 & 20 & 25 & 30 & 35 \\
\hline \multicolumn{6}{|l|}{ Gas yield (mol/kg biomass) } \\
\hline coconut shell & 0.49 & 0.54 & 1.21 & 1.38 & 1.19 \\
\hline palm kernel shell & 3.43 & 3.41 & 3.57 & 3.95 & 3.97 \\
\hline \multicolumn{6}{|l|}{ Gas LHV $\left(\mathrm{kJ} / \mathrm{NM}^{3}\right)$} \\
\hline coconut shell & 323 & 369 & 995 & 1204 & 1067 \\
\hline palm kernel shell & 2877 & 3758 & 3427 & 5578 & 4887 \\
\hline
\end{tabular}

\subsection{Effect of Equivalence ratio (ER)}

Equivalence ratio (ER) was varied from 0.15 to 0.45 by changing the mass flow rate and holding the other conditions constant. The tests results of varying ER were reported in Figure 5 and Table 5 for all agricultural wastes tested. ER was found to have significant influence on the hydrogen production and gas quality. Figure 5 indicates that $\mathrm{H}_{2}$ and $\mathrm{CO}$ content increased first and then decreased as ER increased.

Figure 5. Effect of equivance ratio (ER) on gas composition for palm kernel shell (PKS) and coconut shell (CS).

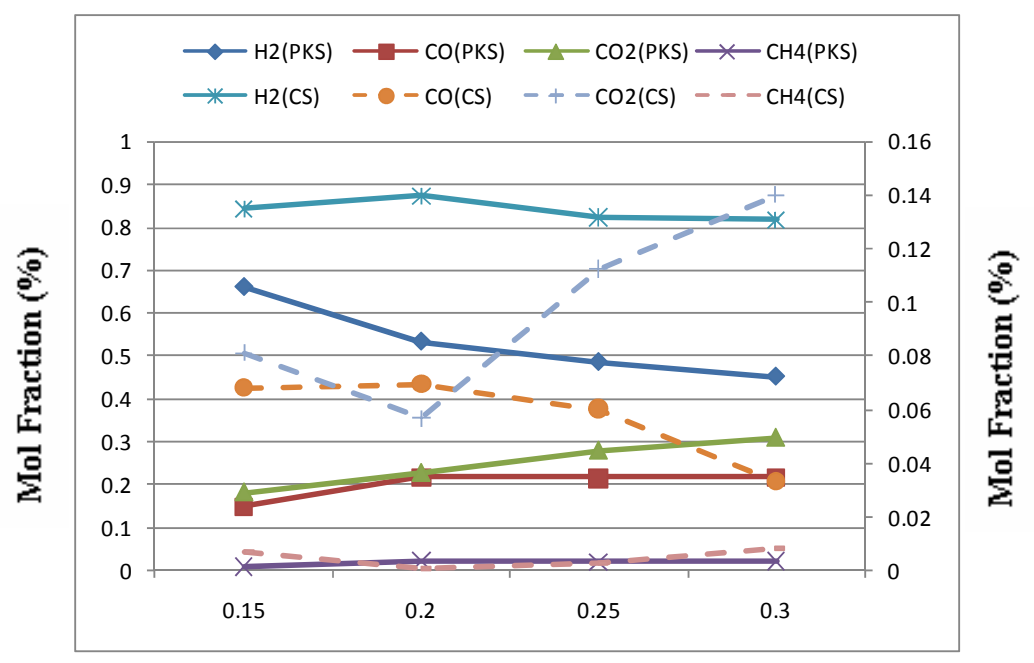

Equivalence ratio (ER)

As stated by Lv et al. [6], ER not only represents the oxygen quantity introduced to the reactor but also affects the gasification temperature under the condition of auto thermal operation. On the one hand, a higher ER will cause gas quality, while on the other hand, higher ER means higher gasification temperature, which can accelerate the gasification and improve the product purity to a certain limit. Therefore the gas composition is affected by the two contradictory factors of ER. Also, Xiao et al. [4] suggested that this increase in $\mathrm{CO}$ and $\mathrm{H}_{2}$ content can be explained as due to thermal cracking of hydrocarbons and tars (reactions 2, 3,4 and 6) at a higher temperature. While the decrease in CO and $\mathrm{H}_{2}$ content with further increase ER due to partial combustion of different gaseous components which resulted a large increase in $\mathrm{CO}_{2}$ concentration. Also, it was noted that a significant decrease in LHV 
from 117 and 2286 to 85 and $1482 \mathrm{~kJ} / \mathrm{NM}^{3}$ for coconut shell and palm kernel shell, respectively with increasing ER due to consumption of hydrocarbons by combustion. The results obtained agree fairly well with previous studies, no matter what was the nature of feed stock gasified [4-8].

Table 5. Gas yield and LHV at different ER.

\begin{tabular}{llllll}
\hline Equivalence Ratio (ER) & $\mathbf{0 . 1 5}$ & $\mathbf{0 . 2 0}$ & $\mathbf{0 . 2 5}$ & $\mathbf{0 . 3 0}$ & $\mathbf{0 . 4 5}$ \\
\hline Gas yield (mol/kg biomass) & & & & & \\
a) coconut shell & 0.31 & 0.41 & 1.08 & 0.64 & 0.25 \\
b) palm kernel shell & 2.7 & 4.02 & 2.81 & 1.86 & 1.08 \\
Gas LHV (kJ/NM ${ }^{3}$ ) & & & & & \\
a) coconut shell & 117 & 190 & 473 & 261 & 85 \\
b) palm kernel shell & 2286 & 2863 & 3467 & 1812 & 1482 \\
\hline
\end{tabular}

\section{Conclusions}

Air gasification of agricultural wastes was successfully performed in a lab scale fluidized bed gasifier, producing a fuel gas with a lower heating value in the range of 85 and $2384 \mathrm{~kJ} / \mathrm{NM}^{3}$ and 1482 and $5578 \mathrm{~kJ} / \mathrm{NM}^{3}$ for coconut shell and palm kernel shell, respectively, which could be used in many end use applications. Among the gasification parameters tested, the equivalence ratio appeared to have the most pronounced effect on the reactor temperature, the gas composition, the gas yield, and the gas heating value. The selection of suitable equivalence ratio would depend on the final use of the gas produced. As a higher equivalence ratio (ER) had complex effects on tests results and there existed an optimal value for this factor, which was different according to different operating parameters. The influence of equivalence ratio on the performance of a gasifer could be regarded as the effect of reactor temperature as the reactor was found to be ER dependent. The fluidizing velocity and static bed height would only show minor effect during the gasification process. The fluidization velocity was observed to have an influence on the gasification process to some extent because it will result in the carryover of fine chars from reactor. The bed height would affect the residence time of gases in the high temperature dense bed. Hence, the rise of the bed height favored tars and hydrocarbon cracking reactions, but too high a bed height showed a negative effect due to formation of large bubbles.

\section{Acknowledgements}

This work is financially supported by the Science Fund Grant by Ministry of Science, Technology and Innovation (MOSTI) of Malaysia (03-01-04-SF0530).

\section{References}

1. Chuah, T.G.; Wan Azlina, A.G.K.; Robiah, Y.; Omar, R. Biomass as the renewable energy sources in Malaysia. Int. J. Green Ener. 2006, 3, 323-346.

2. Bridgwater, A.V. Renewable fuels and chemicals by thermal processing of biomass. J. Chem. Eng. 2003, 91, 87-102. 
3. Lapuerta, M.; Hernandez, J.J.; Pozoz, A.; Lopez, J. Gasification and co-gasification of biomass wastes:effect of the biomass origin and the gasifier operating conditions. Fuel Process. Technol. 2008, doi:10.1016/jfruproc.2008.02.001.

4. Xiao, R.; Jin, B.; Zhou, H.; Zhong Z.; Zhang, M. Air gasification of polyproplynen plastic waste in fluidized bed gasifier. Energy Convers. Manage. 2007, 48,778-786.

5. Gonzalez, J.F.; Roman, S.; Bragado D.; Calderon, M. Investigation on the reactions influencing biomass air and air/steam gasification for hydrogen production. Fuel Process. Technol. 2008, doi:10.1016,j/fuproc.2008.01.011.

6. Lv, P.M.; Xiong, Z.; Chang, H.J.; Chen, Y.; Zhu, J.X. An experimental study on biomass airsteam gasification in a fluidized bed. Bioresour. Technol. 2004, 95, 95-101.

7. Lim, M.T.; Alimuddin, Z. Bubbling fluidized bed biomass gasification-Performance, process findings and energy analysis. Renewable Energy 2008, 33, 2339-2343.

8. Hoque, M.M.; Bhattacharya, S.C. Fuel characteristics of gasified coconut shell in a fluidized and a spouted bed reactor. Energy 2001, 26, 101-110.

9. Ravelli, S.; Perdichizzi, A.; Barigozzi, G. Descriptions, application and numerical modelling of bubbling fluiidzed bed combustion in waste-to-energy plants. Prog. Energy Combust. Sci. 2008, 34, 224-253.

10. Dermibas, A. Gaseous products from biomass by pyrolysis and gasification : effects of catalyst on hydrogen yield. Energy Convers. Manage. 2002, 43, 897-909.

11. Warnecke, R. Gasification of biomasss: comparison of fixed bed and fluidized bed. Biomass Bioenergy 2000, 18, 489-497.

12. Gil, J.; Corella, J.; Aznar, M.P.; Caballero, M.A. Biomass gasification in atmospheric and bubbling fluidized bed: effect of type gasifying agent on the product distribution. Biomass Bioenergy 1999, 17, 389-403.

13. Andre, R.N.; Pinto, F.; Franco, C.; Dias, M.; Gulyurtlu, I.; Matos M.A.A.; Cabrita, I. Fluidised bed co-gasification of coal and olive oil industry wastes. Fuel 2005, 84, 1635-1644

14. Dogru, M. gasification of hazelnut shells. Energy 2000, 27, 415-427.

15. Stiegel, G.J.; Ramezan, M. Hydrogen from coal gasification: an economical pathway to a sustainable future, Int. J. Coal Geol. 2006, 65, 173-190.

16. Van Der Drift, A.; Doorn, J.V.; Vermulen, J.W. Ten residual biomass fuels for circulating fluidized bed gasification. Biomass Bioenergy 2001, 20, 45-56.

17. Tillman, D.A Biomass Cofiring: The Technology, The experience, The Combustion Consequences. Biomass Bioenergy 2000, 19, 365-384.

18. Mansary, K.G.; Ghaly, A.E.; Al -Taweel, A.M.; hamdullahpur, F.; Ugursal, V.I. Air gasification of rice husk in a dual distributor type fluidized bed gasifier. Biomass Bioenergy 1999, 4, 315-332.

(C) 2009 by the authors; licensee Molecular Diversity Preservation International, Basel, Switzerland. This article is an open-access article distributed under the terms and conditions of the Creative Commons Attribution license (http://creativecommons.org/licenses/by/3.0/). 